\title{
Pauropods (Myriapoda: Pauropoda) from Western Australia, with descriptions of a new family, a new genus and three new species
}

\author{
U. Scheller \\ Häggeboholm, Häggesled, S-53194 Järpås, Sweden.
}

\begin{abstract}
A collection of Pauropoda from Western Australia has been studied. Among seven identifiable specimens, four species in three genera have been identified. Three new species are described from the order Tetramerocerata, Stylopauropoides wungongensis sp. nov., S. saxicola sp. nov. and Antichtopauropus brevitarsus gen. nov., sp. nov., the latter also forming a new family in the order Tetramerocerata, Antichtopauropodidae. Decapauropus tenuis Remy is recorded from Western Australia for the first time.
\end{abstract}

KEYWORDS: taxonomy, Tetramerocerata, Pauropodidae, Antichtopauropodidae, soil fauna, biogeography.

\section{INTRODUCTION}

Pauropods are small pale myriapods with distinctive bifurcate antennae. They principally occur in soil but due to their small size are rarely collected. The Australian fauna is relatively small and only the Tasmanian fauna, with 19 species, can be considered better known (Scheller 2009). Only a few species of Pauropoda have been reported from Australia though material has been studied by Harrison (1914), Chamberlin (1920), Tiegs (1943, 1947), Remy (1949, 1957, 1959) and Postle et al. (1991). Only two of these papers dealt with material from Western Australia (Remy 1957; Postle et al. 1991). Remy (1957) described three species, Stylopauropoides bornemisszai, Decapauropus spicatus and D. notius, from Gnangara, c. $30 \mathrm{~km}$ north of Perth, and Postle et al. (1991) reported from near Dwellingup, c. $85 \mathrm{~km}$ south of Perth, the first two of Remy's species and other species from these genera, but also from Allopauropus, Rabaudauropus, Hemipauropus, Scleropauropus, Polypauropoides and a new genus placed in Brachypauropodidae. The collection from Dwellingup is extensive with thousands of specimens but has not yet been described.

Thanks to Dr Mark S. Harvey, curator of arachnids and myriapods at the Western Australian Museum, 11 specimens from three different sites in Western Australia were available for the present study. Though small in number the collection with two new species in Stylopauropoides and one in a new genus, Antichtopauropus, indicates high diversity and local endemism.

All specimens studied in this paper are lodged in the Western Australian Museum, Perth (WAM) and were studied in monopropylene glycol using a Zeiss light microscope. The descriptive terms are listed in Scheller (1988). The body length of the holotype and range of body lengths of adult paratypes are given in $\mathrm{mm}$, adult paratypes in brackets. When relative lengths are used the reference value is stated in the text.

\section{SYSTEMATICS}

\section{Family Pauropodidae Lubbock, 1867 \\ Genus Decapauropus Remy, 1931}

Decapauropus Remy, 1931: 67.

\section{TYPE SPECIES}

Decapauropus cuenoti Remy, 1931 by original designation.

\section{Decapauropus tenuis Remy, 1948}

\section{MATERIAL EXAMINED}

Australia: Western Australia: 1 adult i $(9 \mathrm{leg}$ pairs), Hope Downs Station, $35 \mathrm{~km} \mathrm{NW}$ of Newman, $32^{\circ} 07^{\prime} 22^{\prime \prime} \mathrm{S}, 119^{\circ} 29^{\prime} 35^{\prime \prime} \mathrm{E}$, stygofauna sample, 11 February 2008, P. Bolton, C. Weston (WAM T92109).

\section{DISTRIBUTION}

This species is widely and discontinuously distributed in the tropics and subtropics of the Americas, Africa, southern Asia and Australia, where it was taken from a sugar cane field at Gordonvale in Queensland (Remy 1959). 


\section{Genus Stylopauropoides Remy, 1956}

Stylopauropoides Remy, 1956: 213.

\section{TYPE SPECIES}

Stylopauropoides tiegsi (Remy, 1956) by subsequent designation.

\section{Stylopauropoides wungongensis sp. nov.}

Figures 1-10

\section{MATERIAL EXAMINED}

\section{Holotype}

Australia: Western Australia: adult $\widehat{\partial}$ (9 leg pairs), Wungong Dam, $32^{\circ} 11^{\prime} 41^{\prime \prime} \mathrm{S}, 115^{\circ} 03^{\prime} 33^{\prime \prime} \mathrm{E}$, under stone, 2 June 2008, M.S. Harvey, F. Harvey, E. Harvey (WAM T89545).

\section{DIAGNOSIS}

The pygidium with the anal plate have characters indicating that $S$. wungongensis may be close to a group of species with supposed Gondwanic origin, $S$. bornemisszai Remy from Western Australia (Remy 1957), S. tiegsi Remy from Victoria in eastern Australia (Remy 1949), S. lambda Remy from New Zealand (Remy 1956), S. ringueleti Remy from southern Argentina (Remy 1962) and two species from Tasmania, S. erectus Scheller and S. rounsevelli Scheller (Scheller 2009).

Stylopauropoides wungongensis is distinguished from them all by the large triangular lobe of the pygidial sternum. A lobe of similar shape but smaller is in the Tasmanian S. erectus but other distinguishing characters prevent confusion: the pistil of the temporal organs is in the posterior part in the new species, in the middle in $S$. erectus, the st are straight, clavate and glabrous, not curved, cylindrical and pubescent. Though some characters in Remy's (1957) description of $S$. bornemisszai are lacking, it is evident that $S$. wungongensis is clearly delimitated from it: the setae of the tergal side of the head are subcylindrical in $S$. wungongensis, not distinctly clavate, the tergite $\mathrm{V}$ has $6+4$ setae, not $6+6$, the st are clavate, not cylindrical, and the distal appendages of the anal plate are symmetrical with a central stalk, not unsymmetrical. Stylopauropoides tiegsi and S. lambda are similar but there are very good distinguishing characters in the shape of the pygidial setae and the anal plate. In the Argentinian species of the group, S. ringueleti, the bothriotrix $T_{3}$ and the antennal globulus $g$ are quite different.

\section{DESCRIPTION}

\section{Adult male (holotype)}

Length: $1.01 \mathrm{~mm}$.

Head (Figure 1): setae on tergal side of medium length, subcylindrical striate, only $a_{3}$ of $2^{\text {nd }}$ row tapering, lateral seta $l_{1}$ thin cylindrical. Their relative lengths, $1^{\text {st }}$ row: $a_{1}=a_{2}=10 ; 2^{\text {nd }}$ row: $a_{1}=12, a_{2}=14, a_{3}=17,3^{\text {rd }}$ row: $a_{1}=10, a_{2}=12 ; 4^{\text {th }}$ row: $a_{1}=12, a_{2}=20, a_{3}=21, a_{4}=13$; lateral group setae: $l_{1}=20, l_{2}$ and $l_{3}$ not studied. Ratio $a_{1} / a_{1}-a_{1}$ in $1^{\text {st }}$ row $0.8,2^{\text {nd }}$ row $0.7,3^{\text {rd }}$ and $4^{\text {th }}$ rows 0.9 . Length of temporal organs 0.9 of shortest interdistance; a clavate vesicle in posterior part anterior of $l_{1}$ and $l_{2}$, its length 0.1 of the length of temporal organ. Head cuticle glabrous.

Antennae (Figure 2): segment 4 with at least 3 cylindrical striate blunt setae. Their relative lengths: $p=100, p^{\prime}=62, p^{\prime \prime}=52$. Tergal seta $p 1.1$ times as long as tergal branch $t$. The latter subcylindrical, 1.1 times as long as greatest diameter and 0.8 of the length of sternal branch $s$, that branch 2.2 times as long as greatest diameter; posterodistal corner more truncate than anterodistal one. Seta $q$ cylindrical striate blunt, 0.8 of the length of $s$. Relative lengths of flagella (base segments included) and base segments: $F_{1}=100, b s_{1}=10$; $F_{2}=75, b s_{2}=11 ; F_{3}=92, b s_{3}=11$. The $F_{1} 3.2$ times as long as $t, F_{2}$ and $F_{3} 2.0$ and 2.4 times as long as $s$, respectively. Distal calyces hemispherical. Globulus $g$ short-stalked, 1.2 times as long as wide; $\approx 8$ bracts, capsule somewhat flattened; width of $g 0.9$ of the greatest diameter of $t$. Antennae glabrous.

Trunk (Figures 3, 4): setae of collum segment (Figure 3) subequal in length furcate; primary branch folioform with short oblique pubescence, secondary branch rudimentary cylindrical glabrous; sternite process digitiform without distinct anterior incision; appendages short, caps flat; process and appendages glabrous.

Setae on anterior tergites thin cylindrical striate blunt, more posteriorly pointed; $4+4$ setae on tergite I, $6+6$ on II-IV, $6+4 \mathrm{~V}, 4+2$ on VI. Submedian posterior setae on VI (Figure 4) 0.3 of interdistance and as long as pygidial setae $a_{1}$.

Bothriotricha: relative lengths: $T_{1}=100, T_{2}=104, T_{3}=95$, $T_{4}=108, T_{5}=154$. Axes thin simple straight, only proximal half of $T_{3}$ moderately thickened. Pubescence hairs very short on whole the $T_{5}$, short too on proximal $1 / 5$ of $T_{1}$, $T_{2}$ and $T_{4}$ but distal half there with much longer hairs, ramose distally and arranged in whorls; $T_{3}$ as these bothriotricha but pubescence longer, on distal half also sparse (Figure 5).

Legs (Figures 6, 7): setae on coxa (Figure 6) and trochanter of leg 9 furcate, branches of subequal length, weakly clavate-subcylindrical, with minute pubescence. Corresponding setae on more anterior legs with rudimentary secondary branches. Tarsus of leg 9 (Figure 7) 4.8 times as long as greatest diameter; proximal seta tapering pointed, with minute pubescence distally, distal seta subcylindrical blunt striate. Proximal seta 0.3 of the length of tarsus and twice longer than distal seta. Cuticle of tarsus glabrous.

Genital papillae (Figure 8): widest near middle, 1.7 times as long as greatest width, rounded distally, seta 0.4 of the length of papilla.

\section{Pygidium (Figures 9, 10): glabrous.}

Tergum: posterior margin between st with low 

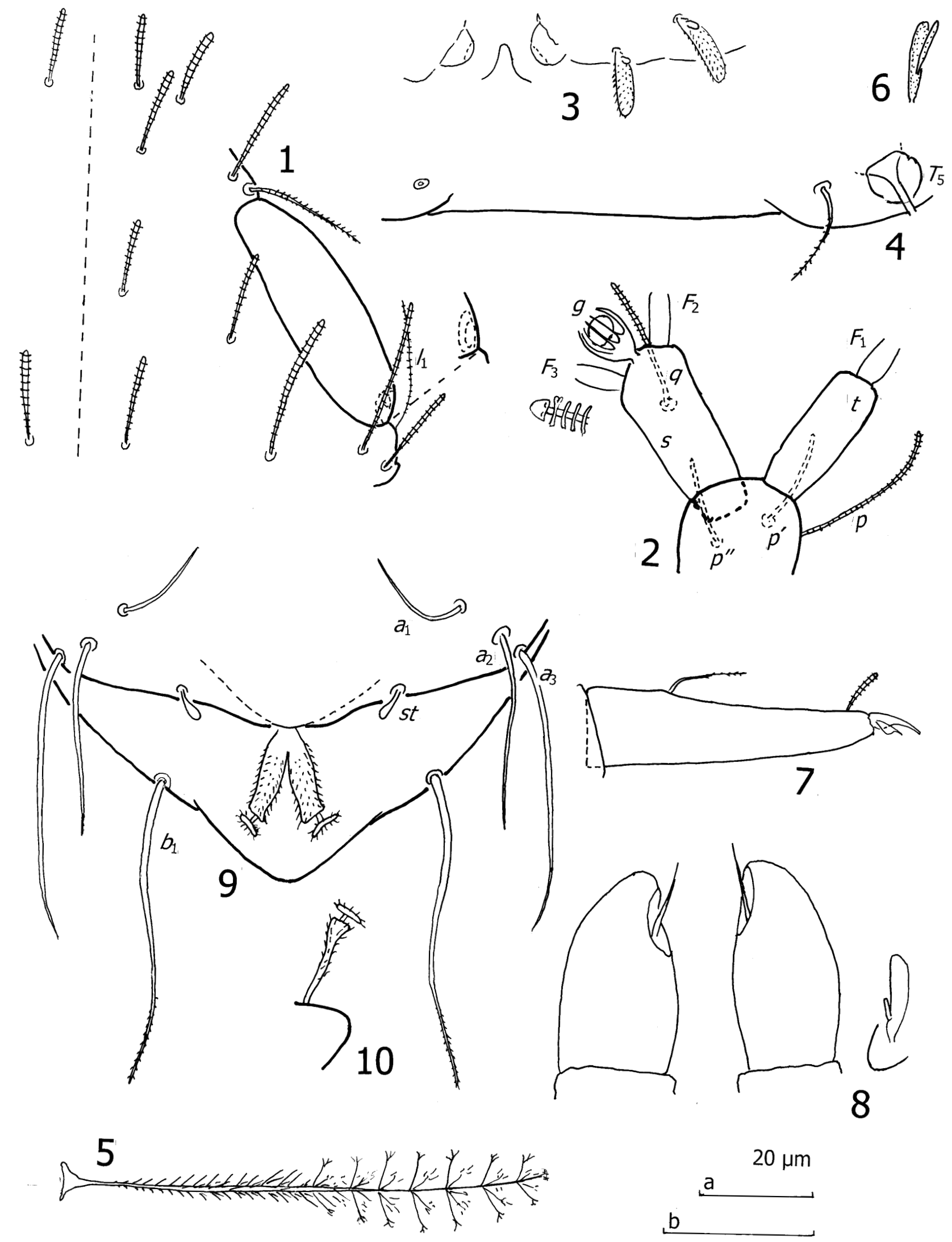

FIGURES 1-10 Stylopauropoides wungongensis sp. nov., holotype, adult male: 1, head, median and right part, tergal view; 2, left antenna, tergal view; 3, collum segment, median and left part, sternal view; 4, tergite VI, posteriomedian part; $5, T_{3} ; 6$, seta on coxa of $9^{\text {th }}$ pair of legs; 7 , tarsus of $9^{\text {th }}$ pair of legs; 8 , genital papillae and seta on coxa of leg 2, anterior view; 9, pygidium, posterior part, tergal view; 10, anal plate, lateral view. Scale a: Figures 5-8; b: Figures 1-4, 9, 10. 


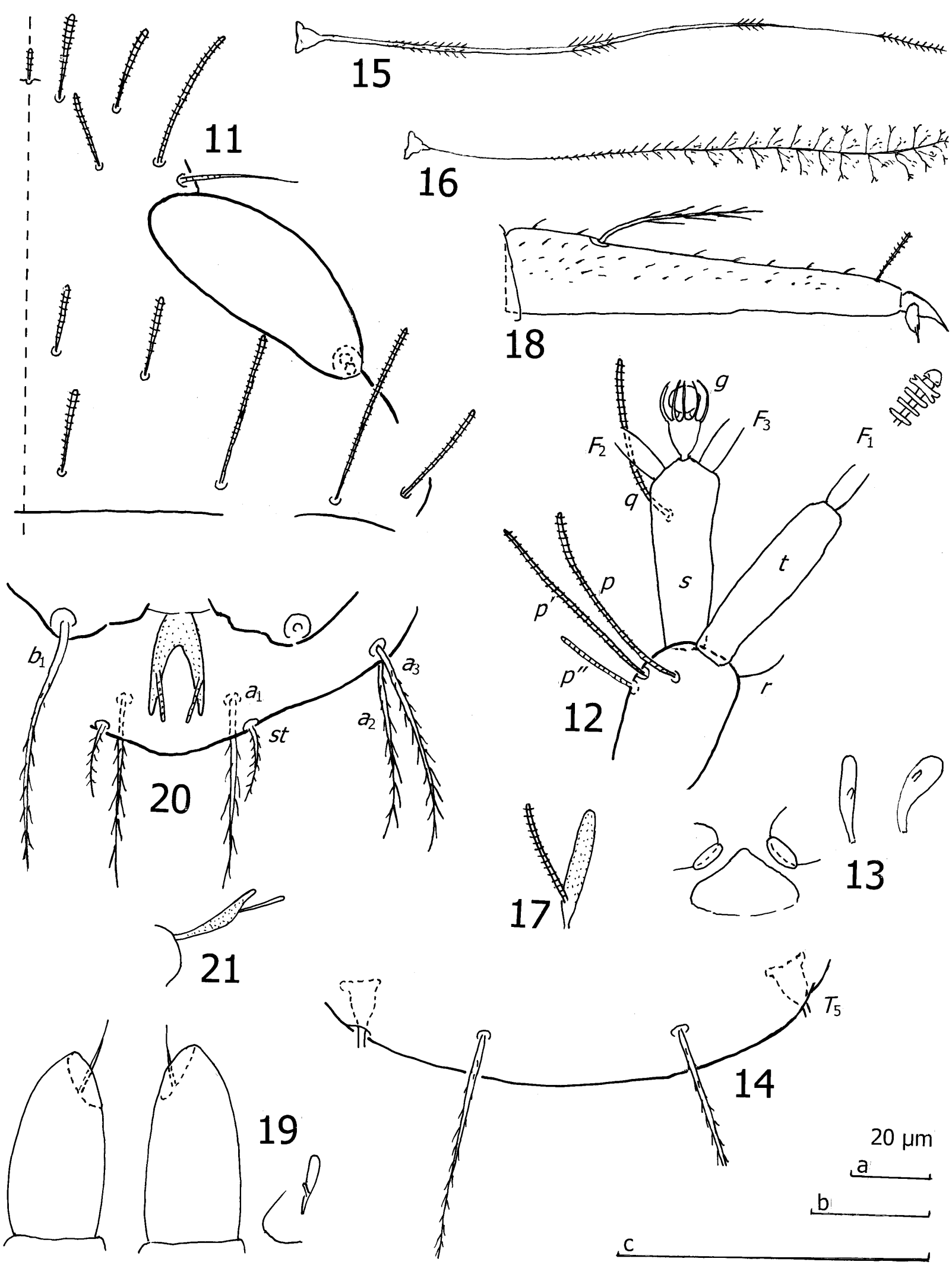

FIGURES 11-21 Stylopauropoides saxicola sp. nov., holotype, adult male: 11, head, median and right part, tergal view; 12, right antenna, tergal view; 13, collum segment, median and left part, sternal view; 14, tergite VI, posteriomedian part. $15, T_{3} .16, T_{1} ; 17$, seta on trochanter of $9^{\text {th }}$ pair of legs; 18 , tarsus of $9^{\text {th }}$ pair of legs; 19, genital papillae and seta on coxa of leg 2, anterior view; 20, pygidium, posteriomedian and left part, sternal view; 21 , anal plate, lateral view. Pubescence only partly drawn in Figure 15. Scale a: Figure 9; b: Figures 5, 8; c: Figures 1-4, 6, 7, 10, 11. 
rounded bulge. Relative lengths of setae: $a_{1}=10, a_{2}=15$, $a_{3}=25, s t=3$. $a$-setae thin tapering pointed glabrous, $a_{1}$ and $a_{3}$ curved inward, the former also converging, st short clavate converging. Distance $a_{1}-a_{1} 3.0$ times as long as $a_{1}$; distance $a_{1}-a_{2} 1.4$ times as long as distance $a_{2}-a_{3}$; distance $s t-s t 7.2$ times as long as $s t$ and 0.6 of distance $a_{1}-a_{1}$.

Sternum: posterior part above $b_{1}$ with large broad triangular lobe. Relative lengths of setae (pygidial $a_{1}=10$ ): $b_{1}=28$. Setae thin tapering, with short pubescence in distal $1 / 3$, length 1.2 times as long interdistance.

Anal plate (Figures 9, 10) almost upright, V-shaped, branches thickest in the middle with weak constriction below posterior end, each branch with a distal appendage in the shape of the head of a thread nail; plate and appendages with distinct pubescence.

\section{ETYMOLOGY}

The epithet of the species name is a latinization of the name of the collecting site.

\section{Stylopauropoides saxicola sp. nov.}

Figures 11-21

\section{MATERIAL EXAMINED}

\section{Holotype}

Australia: Western Australia: adult $\hat{\partial}$ (9 leg pairs), Mundaring Shire, Voyager Quarry, c. $5 \mathrm{~km} \mathrm{NE}$ of The Lakes, 31 $52^{\prime} 05^{\prime \prime S}$, 116 $21^{\prime} 16^{\prime \prime E}$, wandoo litter, 16 July 2002, J.M. Waldock (WAM T95623).

\section{Paratypes}

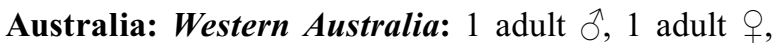
same data as holotype (WAM T99060, T99061).

\section{DIAGNOSIS}

Among the previously described species of Stylopauropoides, S. saxicola sp. nov. is closest to $S$. eximius Scheller, 2009 from Tasmania (Scheller, 2009). These two species have great similarities in the shape of the bothriotricha, the anal plate and the tergites and their setae. Good distinguishing characters are a small linguiform lobe on the posterior part of the pygidial tergum and U-shaped posterior incision in the anal plate in the Tasmanian species, lobe absent and V-shaped incision in S. saxicola. Moreover, the appendages of the anal plate are clavate in the Tasmanian species, not cylindrical. Two more species may belong to the same group, S. vadoni Remy, 1956 from Madagascar and $S$. delamarei (Remy, 1948) from the Ivory Coast (Remy 1948), but they seem to be more distant relatives.

\section{DESCRIPTION}

\section{Adult male holotype (and paratypes)}

Length: 0.92(-0.98) $\mathrm{mm}$.

Head (Figure 11): setae on tergal side of medium length striate, only $a_{3}$ of $2^{\text {nd }}$ row subcylindrical. Their relative lengths, $1^{\text {st }}$ row: $a_{1}=10, a_{2}=10(-11) ; 2^{\text {nd }}$ row: $a_{1}=9(-12), a_{2}=18(-19), a_{3}=14(-16), 3^{\text {rd }}$ row: $a_{1}=8(-10)$, $a_{2}=(9-) 10 ; 4^{\text {th }}$ row: $a_{1}=10(-12), a_{2}=24, a_{3}=23(-25)$, $a_{4}=12(-13)$; lateral group setae: $l_{1}=20, l_{1}$ tapering pointed, $l_{2}$ and $l_{3}$ not studied. Ratio $a_{1} / a_{1}-a_{1}$ in $1^{\text {st }}$ row $(1.3-) 1.4,2^{\text {nd }}$ row $0.6,3^{\text {rd }}$ row $1.1(-1.2), 4^{\text {th }}$ row $1.2(-1.3)$. Length of temporal organs (1.0-)1.2 times as long as shortest interdistance; anterior of $l_{1}$ and $l_{2}$ a two-parted structure in a vesicle, its length 0.1 of the length of temporal organ. Head cuticle glabrous.

Antennae (Figure 12): segment 4 with four cylindrical blunt striate setae, $r$ very thin, their relative lengths: $p=100, p^{\prime}=(82-) 92, p^{\prime \prime}=(43-) 56, r=(23-) 29$. Tergal seta $p$ (as long as-)1.1 times as long as tergal branch $t$. The latter subcylindrical, 6.3(-6.5) times as long as greatest diameter and $(0.8-) 1.0(-1.1)$ of the length of sternal branch $s$, that branch (2.4-)2.7 times as long as greatest diameter; anterodistal corner somewhat more truncate than posterodistal one. Seta $q$ cylindrical striate blunt, 0.9 of the length of $s$. Relative lengths of flagella (base segments included) and base segments: $F_{1}=100, b s_{1}=(8-)$ $9 ; F_{2}=(69-) 71(-77), b s_{2}=(9-) 11 ; F_{3}=(75-) 80, b s_{3}=7$. The $F_{1}(2.7-) 2.8$ times as long as $t, F_{2}$ and $F_{3}(1.9-) 2.1$ and 2.3(-2.6) times as long as $s$ respectively. Distal calyces hemispherical. Globulus $g 1.6$ times as long as wide; $\approx 10$ bracts, capsule spherical; width of $g$ as long as greatest diameter of $t$. Antennae glabrous.

Trunk (Figures 13, 14): setae of collum segment (Figure 13) subequal in length, furcate; primary branch folioform, almost glabrous, secondary branch inserted in the middle, rudimentary cylindrical glabrous; sternite process roundly triangular, blunt anteriorly; appendages short, caps flat; process and appendages glabrous.

Setae on anterior tergites thin cylindrical blunt striate, more posteriorly with oblique pubescence, pointed; $4+4$ setae on tergite I, $6+6$ on II-IV, $4+4$ on $\mathrm{V}, 4+2$ on VI. Submedian posterior setae on VI (Figure 14) as long as interdistance and 1.2(-1.3) times as long as pygidial setae $a_{1}$.

Bothriotricha (Figures 15, 16): relative lengths: $T_{1}=100, T_{2}=67, T_{3}=(80-) 110, T_{4}=172, T_{5}=(189-) 225$. Axes thin simple straight, those in $T_{3}$ (Figure 15) and $T_{5}$ moderately thickened. The $T_{3}-T_{5}$ with short oblique pubescence, hairs short too on proximal $2 / 5$ of $T_{1}$ (Figure 16) and $T_{2}$ but distal half of these bothriotricha sparsely set with long thin erect hairs, in distal part branched.

Legs (Figures 17, 18): setae on coxa and trochanter (Figure 17) of leg 9 furcate, branches of similar length, main branch narrowly folioform with short pubescence, secondary branch cylindrical blunt striate. Corresponding setae on more anterior legs with rudimentary secondary branches. Tarsus of leg 9 (Figure 18) (4.4-)4.6 times as long as greatest diameter. Proximal seta tapering pointed and with long oblique pubescence, distal seta subcylindrical blunt annulate. Proximal seta $0.4(-0.5)$ of the length of tarsus and 2.4 $(-3.1)$ times as long as distal seta. Cuticle of tarsus with very sparse but distinct pubescence on tergal side. 


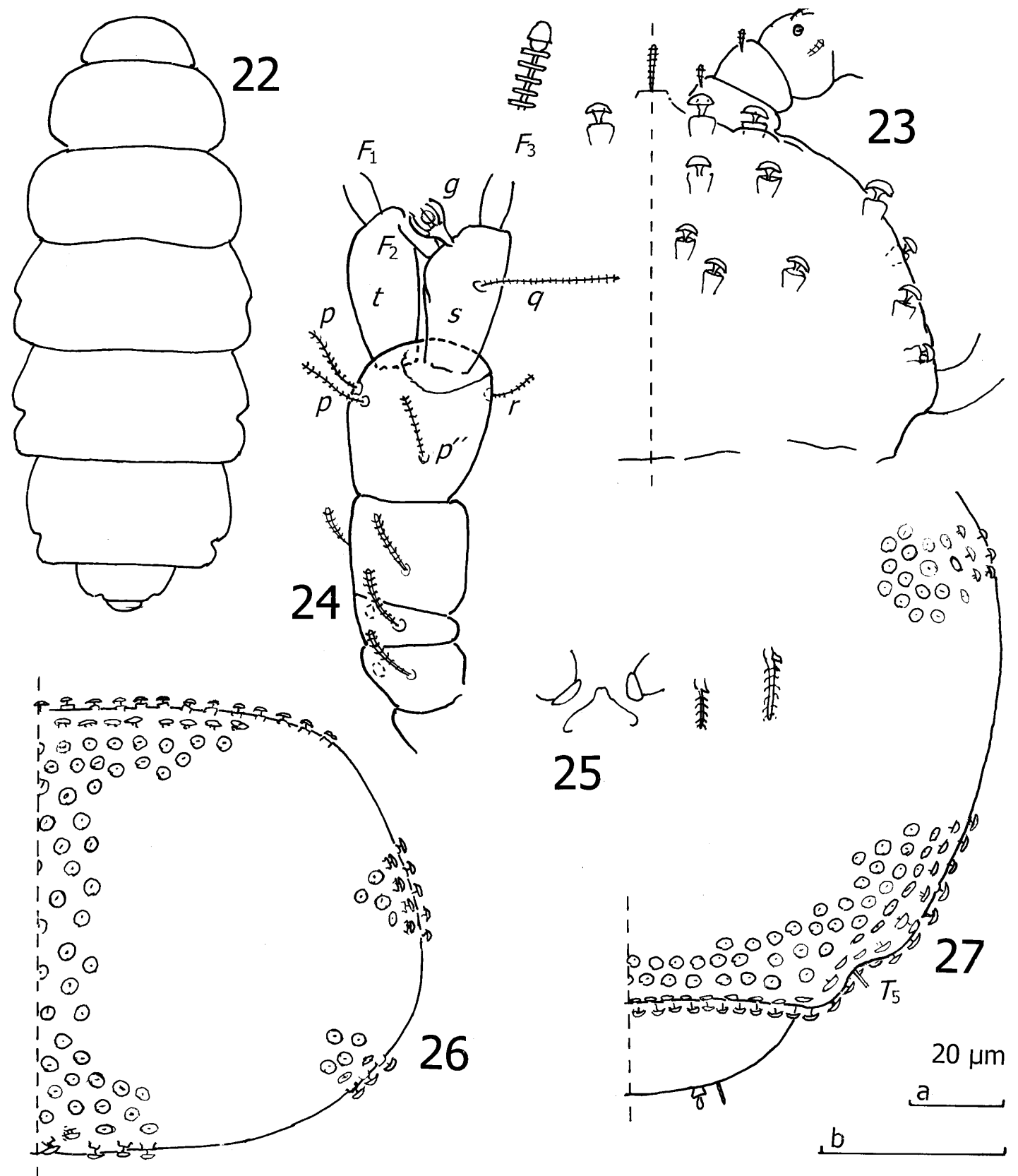

FIGURES 22-27 Antichtopauropus brevitarsus gen. nov., sp. nov., holotype, adult male: 22, body with tergites I-VI; 23, head and proximal part of antenna, right half, tergal view; 24, left antenna, sternal view; 25, collum segment, median and left part, sternal view; 26, tergite II, right half; 27, tergite VI, right posterior part, and pygidium. Fungiform protuberances not drawn in Figure 22, only partly drawn in Figures 25 and 27. Scale a: Figures 26, 27; b: Figures 23-25.

Genital papillae (Figure 19): proximal half cylindrical, distal half conical, evenly rounded, 3.3 times as long as greatest width, seta thin, 0.4 of the length of papilla.

\section{Pygidium (Figures 20, 21): glabrous.}

Tergum: Posterior margin between st with low rounded bulge. Relative lengths of setae: $a_{1}=a_{2}=10$, $a_{3}=10(-12), s t=4$. Setae tapering pointed, with strong oblique pubescence; $a_{1}$, straight, the others curved inward, $a_{3}$ somewhat diverging. Distance $a_{1}-a_{1} 0.6$ of the length of $a_{1}$; distance $a_{1}-a_{2}$ about twice longer than distance $a_{2}-a_{3}$; distance $s t-s t$ twice longer than st and (1.3-)1.4 times as long as distance $a_{1}-a_{1}$.
Sternum. Posterior margin with distinct indentation between $b_{1}$. Relative lengths of setae (pygidial $a_{1}=10$ ): $b_{1}=13$, these setae thin tapering, with pubescence similar to that on setae of tergum; length of $b_{1} 1.1$ times as long as interdistance.

Anal plate (Figures 20,21) directed obliquely upward, twice longer than broad, consisting of two somewhat diverging blunt branches separated by a deep roundly $\mathrm{V}$-shaped incision, length of branches $2 / 3$ of the length of plate; a thin cylindrical appendage protruding backwards from sternal side of each branch, appendages 0.5 of the length of branch, converging; plate with very short pubescence, appendages weakly striate. 


\section{ETYMOLOGY}

From the Latin saxum $=$ stone, and colere $=$ live (referring to the collecting site).

\section{Family Antichtopauropodidae fam. nov.}

\section{DIAGNOSIS}

A family in Pauropoda Tetramerocerata with all tergites entire and sclerotized, without true setae but with protuberances inserted irregularly, tergites I and VI leaving head and pygidium free.

\section{REMARKS}

In Antichtopauropodidae fam. nov. all the tergites are entire as in Eurypauropodoidea and most Pauropodoidea (not entire in Brachypauropodoidea). They are also distinctly sclerotized as in Brachypauropodoidea and Eurypauropodoidea (weakly sclerotized in Pauropodoidea) and tergites I and VI leave the head and the pygidium free as in Pauropodoidea and Brachypauropodoidea (head and pygidium covered by these tergites in Eurypauropodoidea and rarely in Brachypauropodoidea). True setae are absent on the tergites but there are instead a large number of small protuberances, as in some Brachypauropodoidea. This means that the character combination occurring in Antichtopauropodidae is remarkable and shows that it does not agree with any of the superfamilies in current use (Scheller 2008).

\section{Genus Antichtopauropus gen. nov.}

\section{TYPE SPECIES}

Antichtopauropus brevitarsus sp. nov.

\section{DIAGNOSIS}

A genus in Antichtopauropodidae fam. nov. with anterodistal corner of sternal antennal branch more truncate than posterodistal corner, stalk of antennal globulus $g$ distinctly shorter than globulus, $1^{\text {st }}$ and last pair of legs 5-segmented, interposed pairs 6-segmented, pygidial sternum with setae $b_{1}+b_{2}+b_{3}$.

\section{ETYMOLOGY}

From the Greek antichton = southern hemisphere (referring to the locality).

\section{Antichtopauropus brevitarsus sp. nov.}

Figures 22-35

\section{MATERIAL EXAMINED}

\section{Holotype}

Australia: Western Australia: adult ô (9 leg pairs),

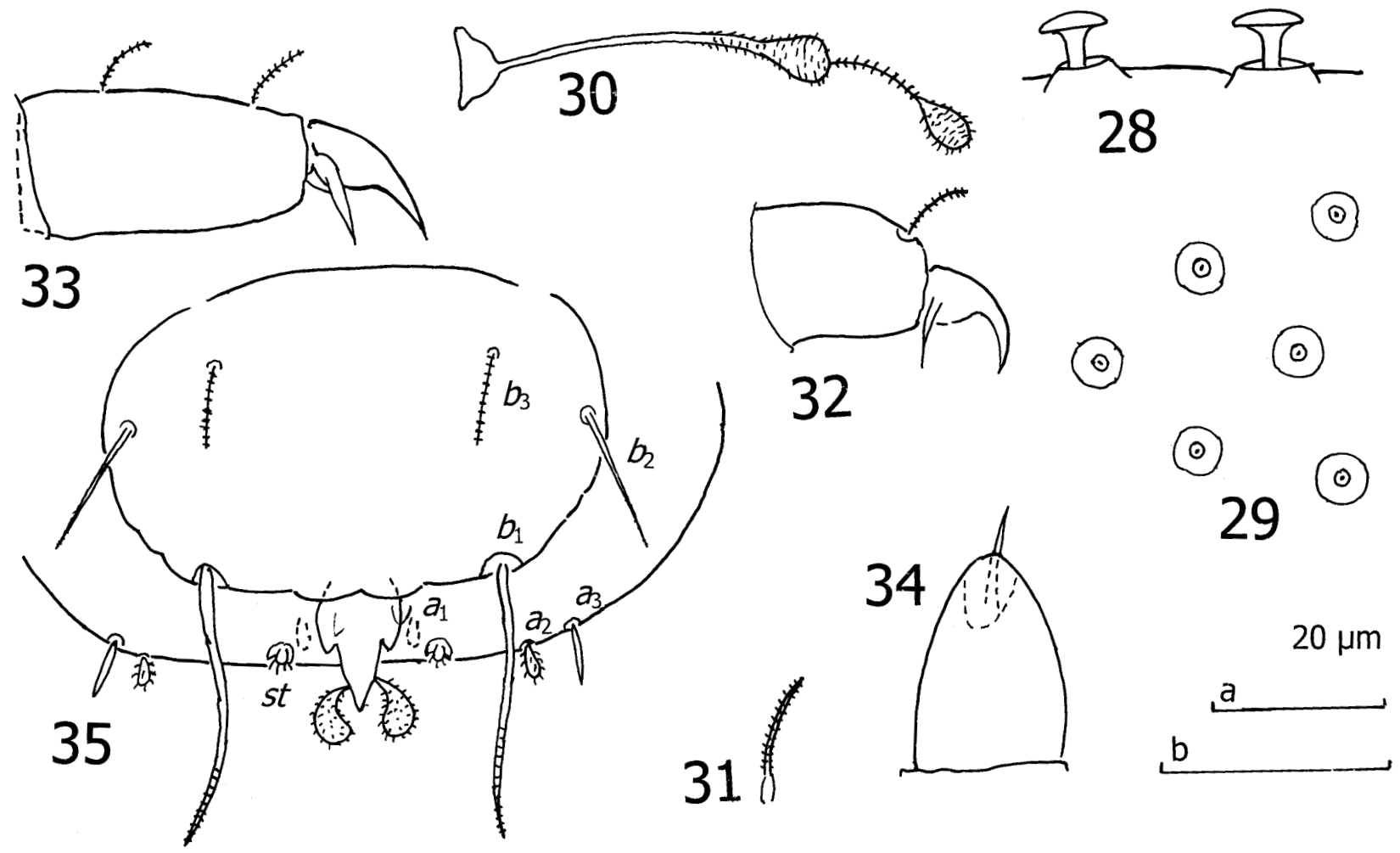

FIGURES 28-35 Antichtopauropus brevitarsus gen. nov., sp. nov., holotype, adult male: 28, fungiform protuberances from tergite I, lateral view; 29 , fungiform protuberances from tergite I, tergal view; $30, T_{3} ; 31$, seta on trochanter of leg 9; 32, tarsus of leg 1; 33, tarsus of leg 9; 34, genital papilla, outer lateral view; 35 , pygidium, sternal view. Scale a: Figures 30-35; b: Figures 28-29. 
Mundaring Shire, Voyager Quarry, c. $5 \mathrm{~km} \mathrm{NE}$ of The Lakes, $31^{\circ} 52^{\prime} 05^{\prime \prime S}, 116^{\circ} 21^{\prime} 16^{\prime \prime} \mathrm{E}$, Tullgren funnel extraction of wandoo litter, 16 July 2002, J.M. Waldock (WAM T99062).

\section{Paratype}

Australia: Western Australia: 1 subadult $\delta$ (8 leg pairs), same data as holotype (WAM T99063).

\section{DESCRIPTION}

\section{Adult male (holotype)}

\section{Length: $0.81 \mathrm{~mm}$.}

Head (Figure 23): a median anterior clavate seta between antennal bases and on each half of tergal and laterotergal side of head at least 11 fungiform tergal and laterotergal protuberances and two thin posterolateral setae. Temporal organs laterosternal, not visible from above, subcircular, no appendages but small pistil posteriorly. Cuticle between protuberances glabrous.

Antennae (Figure 24): segment 4 with four setae, all cylindrical striate-annulate blunt, $r$ thinnest; their relative lengths $p=p^{\prime}=p^{\prime \prime}=10, r=6 ; p 0.5$ of the length of tergal branch $t$. The latter fusiform, distally truncate obliquely, 2.1 times as long as greatest diameter and as long as the length of sternal branch $s$, that branch 1.8 times as long as greatest diameter, anterodistal corner more truncate than posterodistal one. Seta $q$ thin cylindrical blunt striate, as long as the length of $s$. Relative lengths of flagella (base segments included) and base segments: $F_{1}=100, b s_{1}=8 ; F_{2}=36, b s_{2}=6 ; F_{3}=91$, $b s_{3}=8 . F_{1} 4.1$ times as long as $t, F_{2}$ and $F_{3} 1.6$ and 4.0 times as long as $s$ respectively; $F_{2}$ distinctly thinner than $F_{1}$ and $F_{3}$. Distal calyces helmet-shaped, axes widened only between calyx and most distal lamella. Globulus $g$ small, 1.3 times as long as wide; $\approx 6$ bracts, capsule small spherical; width of $g 0.7$ of greatest diameter of $t$. Antennae glabrous.

Trunk (Figures 22, 25-29): setae of collum segment (Figure 25) short furcate; primary branch somewhat tapering striate, secondary branch rudimentary glabrous; sternite process triangular, anterior part blunt; process and appendages glabrous.

Tergites III-VI with shallow indentations around insertion pits of bothriotricha (Figure 22). Tergites (Figures 22, 26-27) distinctly sclerotized, true setae absent but surface densely covered with fungiform organs (Figures 28, 29), surface between fungiform organs glabrous.

Bothriotricha: relative lengths: $T_{1}=100, T_{2}=95$, $T_{3}=67, T_{4}=97, T_{5}=98$. Axes of all but $T_{3}$ thin, with very short pubescence. $T_{3}$ (Figure 30) with thicker axis and two pyriform swellings, about 0.1 of the length of bothriotrix, one just outside the middle and the other distally; axis below swellings with short but distinct pubescence; swellings with short pubescence in whorls.

Legs (Figures 31-33): short. Setae on coxa and trochanter (Figure 31) simple cylindrical striate. Tarsi short, those of leg 1 (Figure 32) and leg 9 (Figure 33) 1.3 and 1.8 times as long as greatest diameter, respectively. Tarsi of leg 1 with one seta; tarsi of leg 9 with two setae, thin cylindrical striate, proximal one 0.2 of the length of tarsus and almost as long as distal seta. Cuticle of tarsi glabrous.

Genital papillae (Figure 34): conical with convex sides, 1.3 times as long as greatest diameter, length of seta 0.5 of the length of papilla.

\section{Pygidium (Figure 35): glabrous.}

Tergum: posterior margin evenly rounded. Setae short, relative lengths: $a_{1}=s t=1, a_{2}=2, a_{3}=5 . a_{1}, a_{2}$ and st clavate with a few but distinct pubescence hairs, $a_{3}$ lanceolate glabrous. Distance $a_{1}-a_{1} 3.2$ times as long as $a_{1}$; distance $a_{1}-a_{2} 2.5$ times as long as distance $a_{2}-a_{3}$; distance st-st 6.5 times as long as st and 1.4 times as long as distance $a_{1}-a_{1}$.

Sternum: posterior margin with two small low bulges just below anal plate. Three pairs of thin setae, $b_{1}$ and $b_{2}$ with indistinct striation distally, $b_{3}$ annulate, their relative lengths (pygidial $a_{1}=10$ ): $b_{1}=77, b_{2}=43, b_{3}=25$. $b_{1} 0.9$ of interdistance, $b_{2} 0.9$ of distance $b_{1}-b_{2}, b_{3} 0.3$ of interdistance.

Anal plate widens from its base with convex lateral margins, a wedge-shaped lobe projecting backward inside two posterolateral corners, lobe twice longer than broad with two curved bladder-shaped appendages projecting outwards-backwards from posterior part, these 0.5 of the length of plate, curved inwards and with short but distinct pubescence.

\section{Etymology}

From the Latin brevis $=$ short and the Greek tarsos $=$ ankle, foot.

\section{REMARKS}

The Western Australian collection reported above, 11 specimens, contained seven identifiable specimens among which four species could be identified, three of them new to science and one (Decapauropus tenuis) belonging to a widespread tropical element. The high number of species in proportion to the number of specimens indicates that the Pauropoda of West Australia show a high degree of endemism and a considerable diversity.

\section{APPENDIX}

A paper on the distribution patterns and diversity of invertebrates of temperate rain forests in Tasmania was published by Greenslade in 2008. The Pauropoda were unreliably treated. Among the many errors some are in a checklist of the species, in which the names of the species not are in accordance with the classification now in use. The key to the species is useless because some genera are named wrongly and most species are not named at all. A new key is presented below. It has, however, to be used with caution because the Tasmanian fauna certainly has more species. Descriptions of the Tasmanian species attributed to me are published in the Memoirs of Museum Victoria (Scheller 2009). 


\section{KEY TO TASMANIAN SPECIES OF PAUROPODA}

1. Body oval, somewhat flattened; tergite I entire, at least tergites II-IV divided; setae of head and tergites more or less modified

Brachypauropodidae

Borneopauropus dignus Scheller

Body fusiform; all tergites entire; setae of head and tergites most often not modified..

Pauropodidae...2

2. Adults with all legs 5-segmented

Nesopauropus tasmaniensis Scheller

Adults with $1^{\text {st }}$ and last pairs of legs 5-segmented, interposed pairs 6-segmented

3. Anterior margin of sternal antennal branch shorter than posterior margin

Anterior and posterior margins of sternal antennal branch subequal in length .11

4. Pygidial sternum with setae $b_{1}, b_{2}$ and $b_{3}$ Allopauropus...5

Pygidial sternum with setae $b_{1}$ and $b_{2}$

Decapauropus...6

5. Temporal organs with distinct anterior appendage; $T_{3}$ with ovoid endswelling; anal plate with long postromedian process

Allopauropus inusitatus Scheller

Temporal organs without anterior appendage; distal part of $T_{3}$ cylindrical; anal plate with straight posterior margin

Allopauropus fraterculus Scheller

6. Bothriotricha $T_{3}$ with ovoid endswelling; pygidial setae $s t$ somewhat clavate.

Decapauropus convexus Scheller

Bothriotricha $T_{3}$ without endswelling; pygidial setae st cylindrical or tapering

7. Pygidial tergum with large rounded posteriomedian lobe; anal plate with very short appendages

Decapauropus terrestris Scheller

Posteriomedian margin of pygidial tergum straight; anal plate with distinct cylindrical or claviform appendages

8. Anal plate with rounded posteriomedian margin....... Decapauropus heis Scheller

Anal plate with posteriomedian incision 9

9. Bothriotricha $T_{3}$ with long ramose pubescence hairs arranged in whorls; proximal and distal setae on tarsus of last pair of legs of the same length....

Decapauropus ungulatus Scheller
Bothriotricha $T_{3}$ with short simple pubescence hairs; proximal seta on tarsus of last pair of legs distinctly longer than distal seta. 10

10. Proximal $2 / 3$ of bothriotricha $T_{3}$ fusiformly thickened; $a$-setae of pygidial tergum pointed.......

Decapauropus attenuatus Scheller

Bothriotricha $T_{3}$ with thin axis; $a$-setae of pygidial tergum cylindrical

Decapauropus saltuarius Scheller

11. Pygidial sternum with setae $b_{1}$ and $b_{2}$ Pauropus...12

Pygidial sternum with setae $b_{1}$ only

Stylopauropoides...13

12. Pygidial setae st subcylindrical tapering; posterior appendages of anal plate short blunt

Pauropus dolosus Remy

Pygidial setae st similar to a knife blade; posterior appendages of anal plate long thin pointed.

.Pauropus vandiemeni Scheller

13. Anal plate with distinct lateral appendages. ..........Stylopauropoides quadripartitus Scheller

Lateral appendages on anal plate absent 14

14. Anal plate with U-shaped posterior incision and clavate appendages ....

Stylopauropoides eximius Scheller

Anal plate with $\mathrm{V}$-shaped posterior incision and appendages in the shape of a drawing-pin... 15

15. Posteriodistal corner of sternal antennal branch $s$ distinctly more truncate than anteriodistal one; pygidial setae $b_{1}$ undulate

Stylopauropoides erectus Scheller

Anteriodistal and posteriodistal corners of sternal antennal branch $s$ equally truncate; pygidial setae $b_{1}$ evenly curved

16. Posteriomedian setae on tergite VI clavate; distal part of bothriotricha $T_{3}$ with simple hairs

Stylopauropoides hetaeros Scheller

Posteriomedian setae on tergite VI thin pointed; distal part of bothriotricha $T_{3}$ with ramose hairs ...

17. Antennal globulus $g$ subspherical; pygidial setae $s t$ tapering pointed

Stylopauropoides rounsevelli Scheller

Antennal globulus $g$ subconical; pygidial setae $s t$ cylindrical..... Stylopauropoides scissus Scheller 


\section{REFERENCES}

Chamberlin, R. (1920). The Myriopoda of the Australian Region. Bulletin of the Museum of Comparative Zoölogy, Harvard College, Cambridge, Massachusetts 64: 1-269.

Greenslade, P. (2008). Distribution patterns and diversity of invertebrates of temperate rainforests in Tasmania with a focus on Pauropoda. Memoirs of Museum Victoria 65: 153-164.

Harrison, L. (1914). On some Pauropoda from New South Wales. Proceedings of the Linnean Society of New South Wales 39: 615-634.

Postle, A.C., Majer, J.D. and Bell, D.T. (1991). A survey of selected soil and litter invertebrate species from the northern jarrah (Eucalyptus marginata) forest of Western Australia, with particular reference to soil-type, stratum, seasonality and the conservation of forest fauna $\mathrm{pp}$. 193-203. In: Lunney, D. (ed.), Conservation of Australia's first fauna. Royal Zoological Society of New South Wales: Sydney.

Remy, P.A. (1931). Un nouveau type de Pauropode: Decapauropus Cuenoti, nov. gen., nov. sp. Archives de Zoologie expérimentale et generale, Notes et Revue, Paris 71: $67-83$.

Remy, P.A. (1948). Pauropodes de la Côte d'Ivoire, Afrique occidentale française. (récoltes de M.Cl. DelamareDeboutteville). Mémoires du Muséum National d'Histoire Naturelle, Paris (n.s.) 27: 115-151.

Remy, P.A. (1949). Sur quelques pauropodes d'Australie.
Memoirs of the National Museum, Melbourne 16: 51-58.

Remy, P.A. (1956). Sur quelques Pauropodes de NouvelleZélande. Bulletin du Muséum National d'Histoire Naturelle, Paris (2)28(1): 213-217.

Remy, P.A. (1957). Pauropodes d'Australie occidentale. Bulletin Société Entomologique de France 62: 136-144.

Remy, P.A. (1959). Pauropodes de l'Île Maurice. The Mauritius Institute Bulletin 5(5): 149-194.

Remy, P.A. (1962). Pauropodes sud-américains. In: Deboutteville, C.D. \& E. Rapoport, Biologie de l'Amerique australe, Ètudes sur la Faune du Sol, Paris, Centre National de la Recherche Scientifique (C.N.R.S., Paris, ed.), vol. 1: 49-61.

Scheller, U. (1988). Pauropoda (Myriapoda) of the Savannah River Plant, Aiken, South Carolina. Savannah River Plant and Environmental Research Park Program (SRO-NERP) 17: 1-99.

Scheller, U. (2008). A reclassification of the Pauropoda (Myriapoda). International Journal of Myriapodology 1: $1-38$.

Scheller, U. (2009). Tasmanian species of Pauropoda (Myriapoda) from temperate rainforests with descriptions of 17 new species. Memoirs of Museum Victoria 66: 289-329.

Tiegs, O.W. (1943). A new species of Pauropus from Victoria. Memoirs of the National Museum of Victoria 13: 151-156.

Tiegs, O.W. (1947). The development and affinities of the Pauropoda, based on a study of Pauropus silvaticus. Quarterly Journal of Microscopical Science 88: 165-267, 275-336, plates 1-11.

MANUSCRIPT RECEIVED 20 OCTOBER 2009; ACCEPTED 6 NOVEMBER 2009. 